\title{
Möjligheter och begränsningar för EU:s aktörskap i södra Kaukasus
}

\author{
Michel Vincent Anderlini` \\ Institutionen för globala politiska studier, Malmö universitet, Sverige
}

\begin{abstract}
EU Actorness in the South Caucasus: Possibilities and Limitations
Despite significant institutional changes and refinements since its creation in 2004, the ENP (European Neighborhood Policy) remains a major tool available to the EU for providing incentives for reform and stability in non-member states through the diffusion of its norms and rules. Earlier studies, drawing on the Europeanization conceptual framework, have been mostly concerned about how and by which mechanisms compliance with EU rules takes place, rather than focusing on whether and to what extent it occurs. By contrast, this article assesses the actorness of the EU in three countries of the South Caucasus (Georgia, Armenia and Azerbaijan), viewing actorness as composed of three dimensions - capability, opportunity, and presence - enabling and constraining the aspirations of the EU to be an international actor in the South Caucasus.
\end{abstract}

Keywords: actorness, South Caucasus, Europeanization, common foreign and security policy

Europeiska unionens förbindelser med de tre länderna i södra Kaukasus (Armenien, Azerbajdzjan och Georgien) bedrivs inom ramen för EU:s grannskapspolitik (European Neighbourhood Policy, ENP) och dess bilaterala dimension, det svenskstödda Östliga partnerskapet (Eastern Partnership, EaP), som ämnar stärka partnerländernas politiska, ekonomiska och sociala integration med EU. Med detta syfte utvecklades ENP 2004 utifrån "utvidgningsmodellen» (Kelley, 2006) med betoning på gemensamma åtaganden för värderingar såsom demokrati, mänskliga rättigheter, rättsstatens principer och god samhällsstyrning. Grannskapspolitiken, till följd av dess ambitioner, omfång och policyverktygslåda, har följaktligen förblivit ett "testfall» för att mäta EU:s påverkansmöjligheter gentemot icke EU-medlemmar (Delcour \& Tulmets, 2009). Något som har genomförts i en rad tidigare studier inom europeiseringsteorin, vilka studerar hur EU:s normer och policyer förflyttas från EU till dess partnerländer (Schimmelfennig, 2012).

ENP har dock genomgått omfattande institutionella förändringar sedan den skapades 2004 och har kommit att lägga större tonvikt på att bygga upp partnerländernas motståndskraft och förbättra säkerhetsförhållanden i regionen (Delcour,

\footnotetext{
^Kontaktinformasjon: Michel Vincent Anderlini, e-post: michel-vincent.anderlini@mau.se 
2015; Nitoiu \& Sus, 2019), något denna artikel kommer att återkomma till. Att mäta EU:s påverkansmöjlighet i Kaukasusregionen behöver därför ta dessa förändringar i beaktande. Denna artikel instämmer med en växande litteratur som hävdar att ENP förvandlats i riktning mot traditionell utrikespolitik, genom vilken EU stödjer partnerländerna både ekonomiskt och politiskt för att uppnå säkerhet och stabilitet bortom sina gränser och inte nödvändigtvis för att närmare integrera dessa med EU (Rieker, 2016; Blockmans, 2017; Batora, 2018). Att mäta hur EU:s påverkansmöjligheter har bidragit till förändringar hos icke-medlemsländer kan därför inte enbart studeras genom att lyfta fram mängden av europeiseringsmekanismer, utan behöver också ta hänsyn till $\mathrm{i}$ vilken utsträckning EU lyckas föra över sinda normer och policyer till ENP-länderna, som saknar trovärdiga medlemskapsutsikter hos EU. Vilka faktorer underlättar normöverförande processer från EU till Kaukasusländerna? Vilka faktorer försvårar dessa?

För att besvara dessa frågor kommer artikeln att använda begreppet aktörskap från Bretherton och Vogler (1999/2006). Begreppet omfattar enligt dessa författare tre olika dimensioner: kapacitet, tillfälle och närvaro. Syftet med denna artikel är således tvådelat: att bidra till att förstå ENP ur ett aktörskapsperspektiv, till skillnad från ett integrationsperspektiv, samt att utvärdera EU:s aktörskap i en regional kontext, Kaukasusregionen. Utvärderingen är särskilt relevant vid denna tidpunkt, eftersom Östliga partnerskapet firade sitt tioårsjubileum 2019 och grannskapspolitiken kommer att ses över under 2020.

Efter en kort historisk bakgrund om EU:s grannskapspolitik och Östliga partnerskapet följer en diskussion om europeiseringteori och om hur begreppet aktörskap anses öka vår förståelse av hur ENP lyckats föra över EU:s normer och policyer i Georgien. Vidare utforskar utvärderingen tre olika aspekter som både möjliggör och begränsar EU:s ambition att vara en internationell aktör i södra Kaukasus utifrån Brethertons och Voglers definition av aktörskap: EU-relaterade, regionala och inhemska processer.

\section{Den europeiska grannskapspolitiken: en kort historisk bakgrund}

"Vad kan vi erbjuda våra grannländer inom en nära framtid? Vilka framtidsutsikter kan vi erbjuda dem? Var slutar Europa? Vi måste besvara dessa frågor. De europeiska medborgarna önskar en sådan debatt. Jag vet att denna debatt kommer att blossa upp efter det att de nya medlemsstaterna anslutits. Det är därför vår plikt att börja finna vissa svar (...) Jag önskar se en 'krets av vänner' som omger unionen och dess närmaste europeiska grannländer, från Marocko till Ryssland och Svarta havet» (Europeiska kommussionen, 2002).

Så löd den dåvarande Europeiska kommissionens ordförande Romano Prodi då han presenterade förslaget på en grannskapspolitik, som utgjorde en reaktion på den kommande "big-bang» utvidgningen 2004 - i och med att en rad politiskt, ekonomiskt och socialt mindre stabila länder helt plötsligt skulle dela gräns med EU 
(Whitman \& Wolff, 2010, s. 3). Den nya grannskapspolitiken sades därför erbjuda de nya partnerländerna en priviligierad relation, baserad på åtaganden gällande mänskliga rättigheter, demokrati, rättsstatens principer, god samhällsstyrning och hållbar utveckling (Schumacher, 2018, s. 3-4). De instrument som skulle bidra till att implementera ENP hämtades från "utvidgningsverktygslådan» - de instrument som gällde för kandidatländerna i Öst- och Centraleuropa skulle bli ENP:s grundstenar: politisk konditionalitet (det vill säga att utvecklingen av varje lands relation är beroende av hur väl landet lever upp till de ovannämnda åtagandena), finansiellt stöd (öronmärkta fonder för ENP) och tekniskt stöd (kapacitetsbyggande insatser såsom TAIEX och Twinning).

Att ENP inspirerades av utvidgningspolitik tydliggjordes även genom att ansvaret för utformningen av ENP låg på generaldirektoratet för utvidgningsfrågor, innan det överfördes till DG RELEX, generaldirektoratet för externa relationer (Kelley, 2006). Den första översynen av ENP, som genomfördes 2011, förstärkte dessa instrument - "mer för mer-principen» infördes (enligt vilket mer reformer i partnerländerna skulle leda till ett ökat engagemang från EU:s sida), tillsammans med ett bredare erbjudande om tillgång till de så kallade 3 "M» (Money, Markets and Mobility) i gengäld för reformer (Europeiska kommissionen, 2003; Bicchi, 2014). Under samma period etablerades grannskapspolitikens två bilaterala plattformar, det svenskstödda Östliga partnerskapet (2009, som innefattar Kaukasusländerna) och Unionen för Medelhavet (2008). Detta illustrerar att »de första åren av grannskapspolitiken var fulla av optimism vad gäller EU:s transformativa potential» (Dandashly \& Noutcheva, 2019, s. 114).

2015 sågs ENP över för andra gången, vilket skedde "mot bakgrund av en övergripande bedömning att politiska förändringar i både det östra och det södra grannskapet medfört att förutsättningarna för grannskapspolitiken hade förändrats» (Riksdagen, 2015, s. 5) - som till exempel kriget mellan Georgien och Ryssland, Armeniens anslutning till Eurasiska ekonomiska unionen samt försämringen av situationen för regimkritiska politiker och civilsamhället i Azerbajdzjan. Det konstaterades därför, i meddelandet som presenterade översynen av ENP, att det fanns "gränser för EU:s inflytande", och att grannskapspolitiken inte hade varit lockande för länderna som inte hade gjort det utrikespolitiska valet att närma sig EU (Europeiska kommissionen, 2015, s. 2). Implementeringen av EU:s principer och normer var ofta selektiv (Bolkvadze, 2016) eller ojämn (Papadimitriou, Baltag \& Surubar, 2017). Mer fokus skulle därför läggas på differentiering (att partnerländerna skulle välja den samarbetsform som passade dem bättre) och egenansvar (beträffande efterlevnad av de EU-normer dessa anammat).

Denna artikel gör gällande att grannskapspolitiken lämnat "utvidgningens skugga» sedan ENP reviderades år 2015 och istället blivit mer lik traditionell utrikespolitik (Delcour, 2015; Rieker, 2016; Blockmans, 2017; Batora, 2018). Bryssel har kommit till insikten att »inte alla partner strävar efter EU:s regler och standarder» och att ENP därför bör återspegla »varje lands önskemål beträffande naturen 
och fokuset av partnerskapet» (Europeiska kommissionen, 2015, s. 2). Som ett led i denna differentiering har ENP istället kommit att handla om att skapa en säkerhetsgemenskap mellan EU och Kaukasusregionen, där partnerländernas stabilitet och motståndskraft mot interna/externa kriser prioriteras framför närmare integration med EU (Rieker, 2016; Batora \& Rieker, 2018). De institutionella förändringar som ENP genomgått sedan 2015 måste beaktas för att kunna utvärdera EU:s påverkansmöjligheter gentemot sitt grannskap. Nästa sektion kommer därför att diskutera tillkortakommanden i europeiseringsteorin, vars integrationsperspektiv dominerat tidigare studier. Aktörskapsbegreppet ger oss en klarare bild över hur normer och principer sprids - partiellt - från EU till länderna i Sydkaukasien.

\section{Europeiseringteori}

Begreppet europeisering har i tidigare forskning använts, enligt Börzel och Risse, i två olika bemärkelser (2002): dels för att klargöra hur "framväxten och utvecklingen av distinkta styrelsenivåer på europeisk nivå, det vill säga av politiska, juridiska och sociala institutioner förknippade med politisk problemlösning, vilket formaliserar interaktioner mellan aktörerna» (Risse, Cowles \& Caporaso, citerat i Iankova, 2009, s. 29). Dels refererar det till de processer och mekanismer genom vilka inhemska politiska strukturer förändras till följd av dessa nya styrelsenivåer och en ökad grad av europeisk integrering (Börzel \& Risse, 2002). Därför har europeiseringteori i stor utsträckning fokuserat på hur EU-medlemsstaternas förvaltning anpassas efter EU-medlemskapet, hur EU-direktiv eller -förordningar implementeras på nationell nivå eller hur nationella identiteter påverkas genom bildandet av en gemensam europeisk identitet (Vink, 2003).

Forskningen inom europeisering kom även att omfatta förändringarna hos kandidatländer under medlemskapsförhandlingar, särskilt efter "östutvidgningen» 2004 (Sedelmeier, 2011). Lanseringen av EU:s grannskapspolitik utgiorde dock en utmaning för forskarna, som gavs i uppgift att studera hur grannskapsländer, som saknar ett trovärdigt medlemskapslöfte från EU, valt att anpassa sitt styrelseskick och sin lagstiftning efter EU:s normer och policyer (Bolkvadze, 2016). Fenomenet kom att betecknas med begreppet EU:s »externa styrning» (Lavenex \& Wichmann, 2009; Lavenex \& Schimmelfennig, 2009) eftersom normöverförande processer även förutsågs inom ramen för EU:s grannskapspolitik, som i sin tur involverar:

a) konstruktion, b) spridning och c) institutionalisering av formella och informella regler, förfaranden, policyparadigmer, stilar, "sätt att göra saker» och delade uppfattningar och normer som först definieras och konsolideras i EU:s politiska process och sedan införlivas $\mathrm{i}$ den inhemska (nationella och subnationella) diskursens logik, politiska strukturer och offentliga val (Radaelli, 2003, s. 30).

Att utvärdera effekten av normöverförande processer i mottagarländerna är dock en svår uppgift: när kan en norm eller en policy anses vara införlivad i nationell kontext? I vissa fall leder normöverförande processer till att partnerländerna antar ny 
lagstiftning. I andra fall följer »en lång process (...) med diskussioner och överläggningar, en kedja av beslut eller, å andra sidan, en serie möten och förhandlingssessioner som under åren inte leder till ett slutligt avtal, men som ändå kan åtminstone ändra några åsikter i vissa länder genom socialisering» (Exadaktylos \& Radaelli, 2012, s. 3). Tidigare studier inom europeiseringsteorin har studerat de olika mekanismer som resulterar i antagandet och implementeringen av normer i ENP-länderna.

Men deras utgångspunkt är att EU:s externa styrning påverkar länderna $\mathrm{i}$ grannskapet och fokus ligger därför på att blottlägga de bakomliggande processerna (Lavenex, 2014; Schimmelfennig, 2018). Frågan om normdiffusion alls sker hamnar i skymundan (Rieker, 2016). Denna artikel hävdar att begreppet aktörskap vidgar undersökningshorisonten till att även inbegripa de lokala och regionala omständigheter som underlättar och förhindrar normöverförande processer (Magen \& Morino, 2009; Hoffmann \& Niemann, 2018). Detta är särskilt angeläget eftersom ENP gradvis har skiftat fokus från ett integrationsperspektiv till mer traditionell utrikespolitik, där partnerländernas önskemål om närmare integrering med EU inte längre tas för givet. Nästa sektion ägnas således åt definitionen av begreppet aktörskap.

\section{EU:s aktörskap}

Forskningsdebatten kring EU:s aktörskap är »en av de längsta inom fältet europeiska studier, vars längd även konkurrerar med den gällande debatten över mellanstatliga kontra överstatliga drivkrafter för EU:s integration» (Rhinard \& Sjöstedt, 2019:4). Tidigare forskning om aktörskap fokuserar på två skilda dimensioner - antingen på det dialektiska förhållandet mellan aktör och struktur eller till på vad som gör en internationell institution till en aktör på den globala arenan (Richard \& Van Hamme, 2013). Det är den senare dimensionen som denna sektion handlar om.

Gunnar Sjöstedt hävdar i The External Role of the European Community att två villkor ska vara uppfyllda för att utöva aktörskap: att aktören påvisar en viss autonomi ifrån de andra aktörerna i det internationella systemet samt en viss koherens i sitt agerande (1977, s. 15). Aktörskap, eller med andra ord "kapacitet att aktivt och medvetet handla i förhållande till andra aktörer i det internationella systemet» (Sjöstedt, 1977, s. 16) är även avhängig aktörens förmåga att formulera intressen och mobilisera resurser, fatta beslut under brådskande villkor och att mobilisera specifika verktyg och relaterade aktörer (Sjöstedt, 1977, s. 16). Jupille och Caporaso (1998) utgick från en fallstudie om EG:s agerande under miljötoppmötet i Rio 1992 och utvidgade begreppet genom att utarbeta fyra dimensioner som kännetecknar en aktör på den globala arenan: sammanhållning (graden till vilken aktören kan formulera sammanhängande policyer och initiativ), auktoritet (att aktören innehar den juridiska befogenheten att agera), autonomi (att aktören har en distinkt identitet och separata intressen som är oberoende av andra aktörer) samt erkännande (att andra enheter i det internationella systemet erkänner, accepterar och interagerar med aktören $\mathrm{i}$ fråga). 
Denna artikel instämmer i Richards och Van Hammes kritik att både Sjöstedts och Jupilles och Caporasos definitioner av aktörskap lägger för stort fokus på aktörens interna attribut och försummar att $i$ »internationella relationer kan ingen aktör betraktas som helt oberoende" (Richard \& Van Hamme, 2013, s. 17). Begreppet aktör definieras därför med Brethertons och Voglers tre dimensioner: kapacitet, tillfälle/möjlighet och närvaro (1999/2006). Kapacitet (capacity) hänvisar till interna faktorer som inverkar på EU:s förmåga att utöva närvaron och svara på tillfällen/ möjligheter utöver dess gränser. Med tillfälle/möjlighet (opportunity) menas de externa faktorer som möjliggör eller begränsar EU:s aktörskap såsom andra internationella aktörer, idéer eller händelser, medan närvaro (presence) refererar till EU:s möjligheter att forma partnerländernas beteenden och förväntningar. Med andra ord fokuserar kapacitet på hur EU använder sig av sina olika policyinstrument för att föra över normer och policyer till partnerländerna, tillfälle/möjlighet på inverkan av andra regionala aktörer eller internationella organisationer på normöverförande processer och närvaro på hur inhemska aktörer ser på dessa.

Denna artikel kommer följaktligen, i linje med tidigare studier som ämnat utvärdera EU:s aktörskap med hjälp av Brethertons och Voglers teoretiska ramverk (Larsen, 2002; Söderbaum et al., 2005; Vogler \& Bretherton, 2006; Papadimitriou \& Petrov, 2012; Niemann \& Bretherton, 2013), vilket har aldrig gjorts i Kaukasusregionen. Artikeln ämnar besvara dessa frågor: vilka faktorer underlättar utövandet av EU:s aktörskap i Kaukasusregionen? Vilka faktorer förhindrar detta? Följande sektion kommer att undersöka EU:s kapacitet i Sydkaukasien.

\section{EU:s begränsade kapacitet i Sydkaukasien}

Dimensionen kapacitet refererar i Brethertons och Voglers aktörskapsbegrepp till hur olika policyer och instrument som EU utvecklat både understödjer och hindrar normöverförande processer till unionens partnerländer, i detta fall inom ramen för ENP. I detta avseende lyfte den tidiga forskningen inom grannskapspolitiken särskilt fram frånvaron av tillräckligt starka incitament för mottagarländer att implementera ofta komplexa och kostsamma reformer, speciellt när ENP inte erbjuder medlemskap i gengäld (Lavenex, 2004; Kelley, 2006). I det avseendet jämfördes framgångar i policyöverförande processer från EU till de före detta kandidatländerna i Centraloch Östeuropa med liknande processer beträffande länder i södra Kaukasus, där det noterades att EU:s aktörskap i hög grad förblivit begränsat (Lavenex \& Schimmelfennig, 2007). Dylika jämförelser mellan "mottagningskontexter» (Delcour, 2018, s. 3) tar dock inte hänsyn till att länderna i södra Kaukasus inte utgjorde suveräna stater förrän i början av 1990-talet, vilket - tillsammans med deras sovjetiska arv fortfarande påverkar deras politiska, ekonomiska, sociala och institutionella system (Delcour, 2018, s. 3)

Dessutom har EU:s grannskapspolitik utvecklats och kommit att erbjuda starkare incitament, som till exempel tillgång till EU:s inre marknad och viseringsfrihet. 
Denna förnyade ambition från EU:s sida kulminerade i undertecknandet av associationsavtalet med Georgien år 2014 som syftar till att "möjliggöra ett politiskt samarbete, ekonomisk kooperation med partnerländerna (...) Huvudinstrumentet för att uppnå dessa mål är exporten av EU:s gemenskapsrätt, acquis communautaire» (Wolczuk et al., 2017, s. 7). I denna fråga utgör konditionalitet en avgörande faktor: att incitament kopplas till strikt övervakning av demokratiska reformers implementering främjar normöverföring från EU till grannskapsländerna (Schimmelfennig \& Scholtz, 2008). Konditionalitetsprincipens effektivitet märktes till exempel när Georgien år 2014 antog en antidiskrimineringsstrategi, då detta utgiorde ett krav för att få viseringsfrihet till EU (Youngs, 2017, s. 181). En ojämn tillämpning av konditionalitetsprincipen försvårar spridningen av EU:s normer, vilket oförmågan att fördöma Azerbajdzjans bristande respekt för mänskliga rättigheter illustrerar. Denna eftergift beror på att ekonomiska och energirelaterade intressen sätts främst (Alieva, 2015) samt på rädsla för att urholka den stabilitet som icke-demokratiska regimer tillför den i övrigt konfliktdrabbade regionen (Börzel \& Lebanidze, 2017).

Det finansiella och tekniska stödet som erbjuds till partnerländerna spelar en avgörande roll för EU:s möjlighet att utöva kapacitet i och med att EU:s gemenskapsrätt är »enorm, djup och tillför omfattande kostnader» (Wolczuk et al., 2017, s. 7) för partnerländerna. Kapacitetsbyggnadsövningar, såsom TAIEX eller Twinning, utgör därför viktiga instrument för att underlätta implementering av EU:s normer och policyer i grannskapet. EU:s stöd har bland annat visat sig vara effektivt vad gäller överförandet av EU:s energi- och migrationsregelverk i Armenien, men mindre relevant beträffande rättsstatens principer (Ademmer \& Börzel, 2013; Delcour \& Wolczuk, 2015).

Det ska noteras att EU enbart förmått Georgien att teckna ett associationsavtal medan Armenien och Azerbajdzjan valt en annan väg (Tartes, 2015). Armenien beslutade i september 2013 att plötsligt överge ett framförhandlat associeringsavtal med EU och istället ansluta sig till Eurasiska ekonomiska unionen. Den azerbajdzjanska nationalförsamlingen drog sig till och med tillbaka från Euronest (den parlamentariska församlingen som omfattar EU-parlamentet samt de nationella församlingarna i Georgien, Ukraina, Moldavien, Armenien och Azerbajdzjan) som en reaktion på en resolution, antagen 2015 , om bristen på respekt för mänskliga rättigheter och rättsstatens principer i landet.

Paradoxalt nog ledde revideringen av ENP, med mindre fokus på "mer-för-merprincipen» till att EU och Armenien lyckades underteckna ett fördjupat partnerskapsavtal i november 2017 (dock inte ett associationsavtal) och att Azerbajdzjan är i färd med att förhandla fram ett nytt övergripande avtal med EU (mandatet gavs till EU-kommissionen i november 2016). I en rapport om implementeringen av ENP fastställer EU-kommissionen att: »framsteg vad gäller att återupprätta relationer till grannländerna genom nya former av skräddarsydda partnerskap (...) har gjort det möjligt att bättre reflektera partnerländernas individuella behov och ambitioner» (Europeiska kommissionen, 2017, s. 4). För att uttrycka det i Brethertons 
och Voglers termer så måste EU:s kapacitet (policyverktyg) hela tiden anpassas till partnerländernas beteende och förväntningar.

Nästa sektion vänder blicken mot den andra dimensionen i Brethertons och Voglers aktörskapsbegrepp, nämligen tillfälle, det vill säga hur andra regionala aktörer och internationella organisationer påverkar normöverföringen från EU till partnerskapsländerna.

\section{Grannskapspolitik i ett komplext regionalt landskap - ett missat tillfälle?}

Förekomsten av andra regionala aktörer, ofta med helt disparata intressen, komplicerar normöverförande processer från EU till länderna i södra Kaukasus (Delcour, 2018, s. 3). Lavenex och Schimmelfennig (2009) betonar att EU:s normer lättare förs över till grannskapsländerna när dessa är starkt beroende av EU och dessutom är mer beroende av EU än andra konkurrerande makter såsom Ryssland. Genom ett eget regionalt integrationsprojekt, Euroasiatiska ekonomiska unionen (EaEU) som trädde i kraft 2015, har Ryssland använt sig av »olika former av påtryckningsmedel, både morot och piska, för att påverka grannländerna i önskad riktning» (Linde, 2015).

Armeniens hastiga beslut att ansluta sig till Euroasiatiska ekonomiska unionen istället för att underteckna ett associationsavtal med EU provocerades fram efter att Ryssland annonserat att Azerbajdzjan skulle förses med vapen (Fayos, 2014). Intresset att behålla Ryssland som en trovärdig allierad i konflikten om NagornoKarabach vägde tungt hos den armeniska ledningen, som dessutom fruktade repressalier i form av ryska handelssanktioner om landet närmade sig EU (Syssoyeva, 2019). Trots att EU:s erbjudande om frihandelsavtal gjorde det möjligt för Armenien att teckna liknande avtal med Ryssland och andra länder tillhörande OSS (Oberoende staters samvälde) innebar medlemskapet i tullunionen EaEU att Armenien accepterade handelsregler som omöjliggjorde parallella frihandelsavtal med EU. Genom att pressa länderna i sitt "nära utland» att ansluta sig till EaEU tvingar Ryssland dem till att välja ett geopolitiskt läger (Delcour \& Kostanyan, 2014).

Handelssanktioner och repressalier riktas också mot icke-medlemmar i EaEU, som Georgien. Ryssland har vid upprepade tillfällen utsatt landet för ekonomiska bestraffningar, som till exempel i mars 2006 när Rosselkhoznadzor, den ryska myndigheten ansvarig för veterinära frågor och växtskyddsfrågor, förbjöd importen av georgiska grönsaker och frukter på grund av "brott mot normerna för mikrobiologisk sammansättning» (RadioFreeEurope/RadioLiberty, 2013). Några dagar senare förbjöds även importen av georgiska viner till Ryssland - denna gång på grund av påstådd närvaro av farliga kemikalier i vinerna - vilket slog hårt mot den georgiska vinindustrin eftersom Ryssland tog emot ungefär sextio procent av Georgiens vinexport (Blomgren, 2006).

Kreml använder även andra instrument för att motarbeta ENP-ländernas närmande till EU, såsom "stöd till politiker och NGO:s med syfte att påverka (...) politik 
och samhällsklimat i en för Ryssland gynnsam riktning, cyberattacker, samt informationsoperationer, framför allt genom internetbaserade medier» (Nilsson, 2018). I sin studie Russian Hybrid Tactics in Georgia noterar Nilsson att en rad proryska, alternativa medier började blomstra i Georgien efter 2012, och avsåg väcka misstro mot både EU och NATO genom att presentera dessa organisationer som hot mot landets nationella intressen och kristna värderingar. Exempelvis målades rättigheter för etniska och sexuella minoriteter upp som något som EU påtvingar Georgien, och lösningen sägs bestå i att anslå en mer neutral utrikes- och säkerhetspolitik för att kunna bevara sin traditionella identitet (Nilsson, 2018b). Liknande desinformationskampanjer har även observerats i Armenien (Sarkisyan, 2017) och - med mer begränsande framgångar - i Azerbajdzjan (Gerber \& Zavisca, 2016).

Nära kopplingar till Ryssland innebär inte alltid att normöverförande processer från EU till grannskapsländerna försvåras (Delcour, 2016). Aktörer inom det ryska näringslivet har ibland befunnits stödja implementeringen av EU-stödda reformer i grannskapet, till exempel gällande telekommunikation i Ukraina, där liberalisering ansågs fördelaktigt (Langbein, 2013). Befintlig forskning har dock inte belagt denna företeelse i Sydkaukasien. Delcour och Wolczuk (2015) har däremot funnit att Kremls påtryckningar fick oväntade effekter i Georgien, eftersom dessa gjorde [Saakasjvili-administrationen] mer beslutsamma att fortsätta sin provästerländska orientering och istället drev på implementeringen av EU-normer i landet (Delcour \& Wolczuk, 2015). Georgiens energisektor illustrerar mönstret. Ryssland chockhöjde priset för eloch gasleveranser till Georgien efter rosenrevolutionen, vilket fick regeringen i Tbilisi att ytterligare diversifiera landets energisektor, såsom EU hade begärt (Ademmer, 2015).

Det kan därför konstateras att de tillfällen som andra regionala aktörer både skapar och stänger i hög grad påverkar EU:s förmåga att forma länderna i Sydkaukasien i önskad riktning. Nästa sektion fokuserar på den tredje dimensionen i Brethertons och Voglers aktörskapsbegrepp, nämligen närvaro, som sätter fingret på hur inhemska aktörer i de sydkaukasiska partnerskapsländerna påverkar normöverföringen.

\section{EU:s närvaro och inhemska aktörer}

Börzel och Risse (2012) menar att tidigare förklaringsmodeller överbetonat EU:s roll i implementeringen av normer i grannskapsländerna. Senare forskning har därför kommit att fokusera på inhemska aktörer som både underlättar och försvårar normöverföring (Delcour, 2018, s. 5), vilket Bretherton och Vogler fångar genom begreppet närvaro.

Partnerländernas politiska eliter sägs förklara variation i inhemsk efterlevnad av EU:s normer. Ademmer och Börzel (2013) jämför implementering av EU-stödda reformer gällande antikorruption, migration och energi i Georgien och Armenien och konstaterar att efterlevnaden varit högre i det förstnämnda landet eftersom reformerna passat regeringens agenda. Att regeringar ställer sig bakom implementeringen 
av EU:s normer innebär dock inte att dessa blir tillämpade i den inhemska kontexten, som Delcour (2013) visar beträffande EU-regler för livsmedelssäkerhet i Georgien. I detta fall så accepterade Saakashvili-administrationen principen av statliga kontroller i livsmedelskedjan men försökte icke desto mindre begränsa deras frekvens och räckvidd.

Grannskapsländernas politiska eliter tenderar att undvika efterlevnad av EU:s normer när dessa riskerar att urholka deras maktbas, till exempel genom att göra det svårare att missbruka statliga resurser för att bedriva valkampanjer eller att manipulera valresultat (Schedler, 2002; Bolkvadze, 2016). Ett uppenbart exempel på detta är att alla tre partnerländerna i Kaukasus ofta bortser från EU:s standarder för mediefrihet.

I Georgien rapporterade OSSE:s särskilde representant för mediefrihet att fler än trettio journalister från bland annat Reuters, Radio Free Europe/Radio Liberty Georgian Bureau, Rustavi 2 channel och Civil.ge utsattes för polisövergrepp i samband med att protester bevakades (OSSE:s särskilde representant för mediefrihet, 2019). Reportrar utan gränser placerar Armenien på plats 61 av 180 länder avseende pressfrihet (Reportrar utan gränser, 2019). Freedom House rapporterar om självcensur, hot och trakasserier mot journalister, särskilt under 2018 års sammetsrevolution när "de flesta TV-kanalerna i början undvek att täcka massdemonstrationerna, medan en liten kontingent av oberoende medier, inklusive Civilnet och Azatutyun, kunde ge en stadigt djupgående rapportering» (Freedom House, 2019). Situationen för mediefrihet är sämst i Azerbajdzjan, med en placering på 166 av 180 länder i Reportrar utan gränsers pressfrihetindex (Reportrar utan gränser, 2019b). Flera oberoende mediaorganisationer i landet har stängts ned, regimkritiska nyhetssidor blockeras och journalister har fängslats, som Europaparlamentet påpekar i en resolution från 2019 (Europaparlamentet, 2019).

Att partnerländernas politiska eliter tenderar att undvika efterlevnad av EU:s normer när dessa riskerar att urholka deras maktbas illustreras också med att de partnerskapsprioriteringar som EU och Azerbajdzjan undertecknat inte inkluderar några insatser för medie- och yttrandefrihet (EEAS, 2018). Av samma anledning har inte den mångåriga dispyten mellan Georgien och EU kring landets utnämningsprocedur av domare till Högsta domstolen lösts, vilken ger alltför stor makt till det georgiska parlamentet och därför till den regerande koalitionen Georgian Dream (EEAS, 2019).

Det inhemska näringslivet kan också spela en avgörande roll i att driva på implementeringen av EU:s normer i grannskapsländerna (Dimitrova \& Dragneva, 2013). Detta eftersom "näringslivet betraktar [EU:s normer] främst som en väg för ekonomiskt samarbete med EU-länderna" genom åtskilliga reformer som syftar på harmonisering av partnerländernas lagstiftning med EU:s acquis (Delcour \& Wolczuk, 2016, s. 14). Men näringslivsaktörer kan också agera som »mäktiga vetospelare» när anpassningen till EU riskerar att skada deras handelsintressen. Georgien har till exempel valt att inte ställa sig bakom EU:s utrikesdeklarationer som riktar 
kritik mot Armenien, Azerbajdzjan, Kazakstan och Iran eftersom dessa länder är viktiga energipartners för landet (Mayer, 2014).

Även civilsamhället kan påverka normöverföringen från EU till grannskapsländerna (Buzogány, 2013). Östliga partnerskapets civilsamhällesforum (Eastern Partnership Civil Society Forum - EaP CSF) som etablerades 2012 fungerar härvidlag som plattform för lokala civilsamhällesorganisationer som vill främja EU:s normer i hemmakontexten (Kostanyan \& Vandecasteele, 2013).

Statsförvaltningen i partnerländerna spelar även den en central roll för tilllämpningen av EU:s regler, inte minst eftersom ansvaret för att genomföra dessa - att utforma utkast till lagförslag, implementera beslut och framlägga utvärderingar - ligger hos byråkrater (Wolczuk, 2009). I Sydkaukasien är statsförvaltningen sällan autonoma organisationer, utan de tar ofta sina direktiv från den politiska sfären (Bolkvadze, 2017; Charkviani, 2019). Den diffusa gränsen mellan tjänstemän och politiker komplicerar normöverföringen till partnerskapsländerna. EU:s regler kan inte implementeras på ett transparent och neutralt sätt om statsförvaltningen är politiserad. Ett uttalat mål för EU:s grannskapspolitik är därför att modernisera partnerskapsländernas statsförvaltningar, vilket bland annat reflekteras i Georgiens associationsavtal. Det faktum att landets departement och myndigheter ännu inte har tillräcklig administrativ kapacitet för att implementera EU:s omfattande reformer gör att normöverförande processer ofta blir selektiva och ofullständiga (Wolczuk et al., 2017).

Diverse inhemska aktörer - politiska eliter, näringslivstoppar, civilsamhällesorganisationer och statstjänstemän - påverkar således EU:s möjlighet att förmå partnerskapsländerna till att anta önskade reformförslag. »Du kan leda hästen till vattnet men inte tvinga den att dricka» som Laure Delcour uttrycker saken (2018b, s. 490).

\section{Avslutningsord}

Vilka faktorer underlättar normöverförande processer från EU till Kaukasusländerna? Vilka faktorer försvårar dessa? Att besvara dessa frågor är ingen lätt uppgift (Baltag \& Romanyshyn, 2018, s. 46) eftersom svaret beror på vilken dimension man tittar på (Blavoukos, 2015). Denna artikel har argumenterat för att europeiseringsteorin, som fokuserar på EU:s integrationspotential, endast ger en del av bilden, eftersom den antar att EU:s externa styrning, nästan på ett självgående sätt, påverkar länderna i grannskapet. Dess fokus ligger därför på att blottlägga de bakomliggande mekanismerna bakom denna påverkan. Genom att följa Brethertons och Voglers (2016) tredimensionella ramverk, som beaktar EU:s kapacitet såväl som regionala tillfällen och inhemsk närvaro i partnerskapsländerna, har artikeln tecknat en långt mer fullständig bild av EU:s aktörsskap i Sydkaukasien: att EU i viss mån har lyckats bli en transformativ kraft i ENP-länderna, men att denna ambition hämmas på olika punkter. Utgångspunkten har därför inte blivit hur normöverförande processen från EU till Kaukasusregionen sker, utan om och till vilken utsträckning dessa 
förekommer. Artikeln drar därför slutsatsen att EU:s möjlighet att utöva aktörskap är avhängig kraften i dess instrument men också de tillfällen som konkurrerande regionala makter öppnar och stänger, samt hur inhemska aktörer i partnerskapsländerna ställer sig till EU:s reformförslag. Normöverförande processer från EU till Georgien, Armenien och Azerbajdzjan kan därför bäst beskrivas som selektiva (Vachudova, 2005; Bolkvadze, 2016) eller ojämna (Noutcheva, 2012, s. 16) med stor variation mellan länder och områden. Detta har understrukits i en rapport från Österreichische Gesellschaft für Europapolitik, som konstaterar att "de demokratiska och socioekonomiska reformerna i EaP-länderna har de senaste tio åren genomgått upp- och nedgångar» (Wolfschwenger, 2019, s. 3), vilket även erkänts av EU som i 2015 års översyn av grannskapspolitiken medger "gränser för EU:s inflytande».

Att EU:s aktörskap förblivit begränsat i Kaukasusregionen, som artikeln har påvisat, bör leda till en bredare reflektion om den framtida utformningen av ENP. Detta är särskilt angeläget i och med att den tredje översynen av EU:s grannskapspolitik ska presenteras senare under 2020. I juni 2019 inleddes en samrådsprocess $i$ avsikt att "kritiskt titta på utmaningarna och reflektera över hur man säkerställer att det östliga partnerskapet förblir relevant och inkluderande» (Europeiska kommissionen, 2019) som är nu avslutad. Kommer ENP att ta ytterligare steg mot differentiering, gemensamt ägarskap och flexibilitet, precis som i 2015? Det finns åtminstone sådana tecken: i ett seminarium i Kiev pekade Luc Devigne, EEAS direktör för Ryssland, Östliga partnerskapet, Centralasien och OSSE på den utbredda korruptionen i grannskapet, och hur uteblivna reformer inom rättsväsendet underminerade betydelsen av ENP. Devigne underströk att "vi [EU] röstar inte, utser inte tjänstemän, utser inte domare» i grannskapsländerna (Makszimov, 2019). EU kan därför inte ersätta det ansvar som varje land har för att säkerställa good governance i hemmakontexten, vilket är nödvändigt för att kunna implementera EU-stödda normer och policyer.

Å andra sidan önskar de tre "föregångsländerna» (front-runners) inom Östliga partnerskapet (det vill säga de tre länder som undertecknat associationsavtal med EU: Ukraina, Moldavien och Georgien) större ambitioner med ENP och fler samarbetsformer (Makszimov, 2019b). Den litauiska EPP-delegationen har ställt sig bakom en sådan propå. EU borde, enligt denna, utarbeta en särskild "strategi 2030 för associationstrion» som erbjuder Georgien, Ukraina och Moldavien fler samarbetsprogram, till exempel vad gäller transport- eller miljöpolitik (Lithuanian Delegation of the EPP Group in the European Parliament, 2019). EU-kommissionen är dock skeptisk till att utöka ENP:s ambitioner och räckvidd (Makszimov, 2019b).

Oavsett hur översynen artar sig kvarstår en övergripande fråga, som har hängt sig kvar sedan lanseringen av EU:s grannskapspolitik - har ENP en slutdestination? Frågan är särskilt relevant för de tre föregångsländer eftersom dessa önskar påbörja medlemskapsförhandlingar i framtiden (Gebhard, 2010, s. 103). Detta lyftes fram av David Zalkaliani, Georgiens utrikesminister, i december 2019: 
[A]tt påbörja förhandlingar om associeringsavtalet var det första målet som regeringen, oppositionen, det civila samhället arbetade för. Det uppnåddes och vi hade ett annat mål - viseringsfrihet med EU. Det har också uppnåtts. Det vi behöver nu är ett annat, slutgiltiga mål. Det hjälper till att konsolidera vårt samhälle igen och motiverar också regeringen att påskynda reformprocessen. Att uttrycka beredskap att påbörja medlemsförhandlingar skulle vara ett sådant mål. (Wrobel, 2019)

Dock verkar aptiten för ytterligare utvidgningar liten i Bryssel, med tanke på att medlemsstaterna inte stödde förslaget om att öppna medlemskapsförhandlingar med Nordmakedonien och Albanien i oktober 2019 (Palme, 2019). Frankrikes bidrag till det ovannämnda samrådet om den nya ENP gällande ENP och EaP betonar att "vår ansvarsanda måste kollektivt skydda oss från att främja illusioner eller tvetydighet bland våra partners om syftet med partnerskapet» (Jozwiak, 2020). Det Östliga partnerskapet är enligt Frankrike baserat på politiskt samarbete men exkluderar "alla möjligheter eller alla mekanismer för EU-integration eller medlemskap»" (ibid.). Detta påminner om Christopher Hills tes om att EU lider av en klyfta mellan de utomståendes förväntningar på unionen och dess möjlighet att infria dessa förväntningar (1993, se också Toje, 2008).

Bristen på en uppenbar slutdestination med ENP är mindre betydelsefull för länder som har lägre ambitioner på sin relation till EU (Armenien och Azerbajdzjan). I föregångsländer som Georgien är dock risken påtaglig att EU skadar sin förmåga att infria de inhemska aktörernas förväntningar och förblir en begränsad aktör. Det varnade den tidigare ordföranden i Europeiska rådet Donald Tusk för efter ett besök i Tbilisi år 2015: »i Georgien måste man vara väldigt reserverad och försiktig när det gäller löftet om EU-medlemskap eftersom det verkar orealistiskt inom överskådlig framtid. Ju mer gästvänliga georgierna är, desto värre känner jag mig - även om jag erbjuder en hel del konkreta saker, sviker jag mina värdar i de viktigaste frågorna» (Wrobel, 2019). Eller, för att uttrycka det med andra ord, måste EU:s kapacitet (policyverktyg) hela tiden anpassas till partnerländernas beteenden och förväntningar (närvaro) för att EU ska kunna utöva aktörskap, vilket tidigare påpekats i denna artikel.

\section{Referenser}

Ademmer, E. (2015). Interdependence and EU-demanded policy change in a shared neighbourhood. Fournal of European Public Policy, 22(5), 671-689.

Ademmer, E. \& Börzel, T. (2013). Migration, energy and good governance in the EU's Eastern Neighbourhood. Europe-Asia Studies, 65(4), 581-608.

Alieva, L. (2015, 19. maj). The Eastern Partnership: the view from Azerbaijan. ECFR Commentary. Hämtad 5. december 2019 från https://www.ecfr.eu/article/commentary_azerbaijan3023.

Baltag, D. \& Romanyshyn, I. (2018). The challenge of analysing the performance of the European Neighbourhood Policy. IT. Schumacher, A. Marchetti \& T. Demmelhuber (Red.), The Routledge handbook on the European Neighbourhood Policy (s. 39-50). Milton Park, Abingdon, Oxon: Routledge.

Batora, J. (2018). EU-supported reforms in the EU Neighbourhood as organized anarchies: The case of postMaidan Ukraine. Fournal of European Integration, 40(4), 461-478.

Batora, J. \& Rieker, P. (2018). EU-supported reforms in the EU neighbourhood as organized anarchies: The case of post-Maidan Ukraine. Fournal of European Integration, 40(4), 461-478. 


\section{8 MICHEL VINCENT ANDERLINI}

Bicchi, F. (2014). "Lost in transition»: EU foreign policy and the European Neighbourhood Policy post-Arab spring. L'Europe en Formation, 2014/1(371), 26-40.

Blavoukos S. (2015) Capturing the EU's international performance: An analytical framework. I S. Blavoukos, D. Bourantonis \& C. Portela (Red.), The EU and the non-proliferation of nuclear weapons. The European Union in international affairs (s. 12-30). London: Palgrave Macmillan.

Blockmans, S. (2017). The obsolescence of the European Neighbourhood Policy. CEPS, Brussels. Hämtad 25. maj 2020 från https://www.ceps.eu/download/publication/?id=10266\&pdf=Blockmans $\% 20-\% 20$ Obsolence \%20of\%20the \%20European \%20Neighbourhood\%20Policy.pdf

Blomgren, J. (2006, 24. april). Rysk vinbojkott pressar Georgien. Svenska Dagbladet. Hämtad 07. januari från https://www.svd.se/rysk-vinbojkott-pressar-georgien.

Bretherton, C. \& Vogler, J. (1999/2006). The European Union as a global actor. New York: Routledge.

Bolkvadze, K. (2016). Cherry picking EU conditionality: Selective compliance in Georgia's hybrid regime. Europe-Asia Studies, 68(3), 409-440.

Bolkvadze, K. (2017). Hitting the saturation point: Unpacking the politics of bureaucratic reforms in hybrid regimes. Democratization, 24(4), 751-769.

Buzogány, A. (2013). Selective adoption of EU environmental norms in Ukraine. Convergence à la Carte. Europe-Asia Studies, 65(4), 609-630.

Börzel, T. \& Lebanidze, B. (2017). 'The transformative power of Europe' - beyond enlargement: The EU's performance in promoting democracy in its neighborhood. East European Politics, 33(1), 17-35.

Börzel, T. \& Risse, T. (2002). When Europe hits home: Europeanization and domestic change. European Integration online Papers (EIoP), 4(15).

Börzel, T. \& Risse, T. (2012). From Europeanisation to diffusion: Introduction. West European Politics, 35(1), $1-19$.

Charkviani, T. (2019). Public management culture and meritocracy in Georgia - through the prism of development of state institutions. Fournal of Politics and Democratization, 4(1), 20-45.

Dandashly, A. \& Noutcheva (2019). Unintended consequences of EU democracy support in the European Neighbourhood. The International Spectator: Italian fournal of International Affairs, 54(1), 105-120.

Delcour, L. (2013). Meandering Europeanisation. EU policy instruments and policy convergence in Georgia under the Eastern Partnership. East European Politics, 29(3), 344-357.

Delcour, L. (2015). The 2015 ENP review: Beyond stocktaking, the need for a political strategy. College of Europe Policy Brief, 1(15), 1-4.

Delcour, L. (2016). Multiple external influences and domestic change in the contested neighborhood:The case of food safety. Eurasian Geography and Economics, 57, 43-65.

Delcour, L. (2018). The EU and Russia in their 'contested' neighbourhood: Multiple external influences, policy transfer and domestic change. Routledge Studies in European Foreign Policy, London: Routledge

Delcour, L. (2018b). 'You can lead a horse to water, but you can't make it drink': the EU's and Russia's intersecting conditionalities and domestic responses in Georgia and Moldova. European Politics and Society, 19(4), 490-505.

Delcour, L. \& Kostanyan, H. (2014). Towards a fragmented neighbourhood? EU's and Russia's Policies and their consequences on the area that lies in-between. CEPS Essay 17. Brussels: CEPS.

Delcour, L. \& Tulmets, E. (2009). Pioneer Europe? The ENP as a test case for EU's foreign policy. European Foreign Affairs Review, 14, 501-523.

Delcour, L. \& Wolczuk, K. (2015). Spoiler or facilitator of democratization: Russia's role in Georgia and Ukraine. Democratizaton, 22(3), 459-478.

Delcour, L. \& Wolczuk, K. (2016). Perceptions and images of the EU in the Caucasus. Cascade: Exploring the security-democracy nexus in the Caucasus, Work Package 9 - Deliverable 1. Hämtad 16. januari 2020 från http:/www.cascade-caucasus.eu/wp-content/uploads/2016/09/PERCEPTIONS-AND-IMAGES-OFTHE-EU-IN-THE-CAUCASUS_Delcour_Wolczuk.pdf.

Dimitrova, A. \& Dragneva, R. (2013). Shaping convergence with the EU in foreign policy and state-aid in postOrange Ukraine: Weak external incentives, powerful veto players. Europe-Asia Studies, 65(4), 658-681.

EEAS. (2018, 11. juli). Partnership priorities between the EU and Azerbaijan reinforce the bilateral agenda. Hämtad 14. januari 2020 från https://eeas.europa.eu/headquarters/headquarters-homepage/48244/ partnership-priorities-between-eu-and-azerbaijan-reinforce-bilateral-agenda_en

EEAS. (2019, 13. december). Statement by the Spokesperson on the appointment of judges to the Supreme Court of Georgia. Hämtad 14. januari 2020 från https://eeas.europa.eu/headquarters/headquartershomepage/72068/statement-spokesperson-appointment-judges-supreme-court-georgia_en 
Exadaktylos, T. \& Radaelli, C. M. (Red.) (2012). Research design in European studies: Establishing causality in Europeanization. Basingstoke: Palgrave Macmillan.

Europaparlamentet. (2019). Europaparlamentets resolution av den 17 januari 2019 om Azerbajdzjan, särskilt fallet Mehman Hüseynov. (2019/2511(RSP). Hämtad 14. januari 2020 från https://www.europarl. europa.eu/doceo/document/TA-8-2019-0033_SV.html

Europeiska kommissionen. (2002, 5. december). Ett utvidgat Europa - Närhetspolitik som nyckeln till stabilitet. Tal av Europeiska kommissionens ordförande vid den sjätte konferensen ECSA-World »Fred, säkerhet och stabilitet Internationell dialog om EU:s roll», Bryssel. Hämtad 7. november 2019 från https://europa. eu/rapid/press-release_SPEECH-02-619_sv.htm

Europeiska kommissionen. (2003). Communication from the Commission to the Council and the European Parliament: Wider Europe - Neighbourhood: A new framework for relations with our Eastern and Southern neighbours. COM(2003) 104. Hämtad 7. november 2019 från https://eur-lex.europa.eu/legalcontent/en/TXT/?uri=celex:52003DC0104

Europeiska kommissionen. (2015). Gemensamt meddelande till Europaparlamentet, Rådet, Europeiska Ekonomiska och Sociala Kommittén samt Regionkommittén: Översyn av den europeiska grannskapspolitiken. JOIN(2015) 50 final. Hämtad 7. november 2019 från https://ec.europa.eu/neighbourhood-enlargement/ sites/near/files/neighbourhood/pdf/key-documents/151118_joint-communication_review-of-the-enp_ sv.pdf

Europeiska kommissionen. (2017). Joint Report to the European Parliament, the Council, the European Economic and Social Committee and the Committee of the Regions: Report on the Implementation of the European Neighbourhood Policy. Hämtad 3. december 2019 från https:/eeas.europa.eu/sites/eeas/ files/2_en_act_part1_v9_3.pdf

Europeiska kommissionen. (2019). Eastern Partnership structured consultation. Hämtad 19. januari 2019 från https:/ec.europa.eu/neighbourhood-enlargement/tenders/consultation_eap_en

Fayos, F. (2014). The signature of the Eurasian Union Treaty: A difficult birth, an uncertain Future. European Parliament: Directorate-General for External Policies. Hämtad 7. januari 2020 från http://www.europarl. europa.eu/RegData/etudes/IDAN/2014/536391/EXPO_IDA(2014)536391_EN.pdf

Freedom House. (2019, 5. juni). The Freedom House and the press freedom in Armenia. Hämtad 14. januari 2020 från https://uic.am/en/7669.

Gebhard, C. (2010). The ENP's strategic conception and design overstretching the enlargement template? I R. G. Whitman \& S.Wolff (Red.), The European Neighbourhood Policy in perspective: Context, implementation and impact (s. 89-109). Basingstoke: Palgrave Macmillan.

Gerber, T. P. \& Zavisca, J. (2016). Does Russian propaganda work? The Washington Quarterly, 39(2), 79-98.

Hill, C. (1993). The capability-expectations gap, or conceptualizing Europe's international role. Fournal of Common Market Studies, 31(3), 305-328.

Hoffmann, N. \& Niemann, A. (2018). EU actorness and the EU Neighbourhood Policy. I T. Schumacher, A. Marchetti, \& T. Demmelhuber (Red.), The Routledge handbook on the European Neighbourhood Policy (s. 28-38). Milton Park, Abingdon, Oxon: Routledge.

Iankova, E. (2009). Business, government, and EU accession: Strategic partnership and conflict. Lanham: Rowman \& Littlefield Publishing Group, Inc.

Jozwiak, R. (2020, 27. januari). France: Eastern Partnership doesn't mean EU membership. Radio Free Europe/ Radio Liberty. Hämtad 28. januari 2020 från https:/www.rferl.org/a/france-eastern-partnership-doesn-tmean-eu-membership/30400380.html

Jupille, J. \& Caporaso, J. A. (1998) States, agency, and rules: The European Union in global environmental politics. I C. Rhodes (Red.), European Union in the World Community (s. 213-230). London: Lynne Rienner Publishers.

Kelley, J. (2006). New wine in old wineskins: Promoting political reforms through the New European Neighborhood Policy. Fournal of Common Market Studies, 44(1), 29-55.

Kostanyan, H. \& Vandecasteele, B. (2013). The socialization potential of the Eastern Partnership Civil Society Forum. Eastern Fournal of European Studies, 4(2), 95-110.

Langbein, J. (2013). Unpacking the Russian and EU impact on policy change in the Eastern Neighborhood: The case of Ukraine's telecommunications and food safety. Europe-Asia Studies, 65(4), 631-657.

Larsen, H. (2002). The EU: A global military actor? Cooperation and Conflict, 37(3), 283-302.

Lavenex, S. (2004). EU external governance in wider Europe. Fournal of European Public Policy, 11(4), 680-700.

Lavenex, S. (2014). The power of functionalist extension: How EU rules travel. Fournal of European Public Policy, 21(6), 885-903. 
Lavenex, S. \& Schimmelfennig, F. (2007). Relations with the wider Europe. Fournal of Common Market Studies, 45(1), 143-162.

Lavenex, S. \& Schimmelfennig, F. (2009). EU Rules beyond EU borders: Theorizing external governance in European politics. Fournal of European Public Policy, 16(6), 791-812.

Lavenex, S. \& Wichmann, N. (2009). The external governance of EU internal security. Fournal of European Integration, 31(1), 83-102.

Linde, F. (2015, 10. februari). Ekonomisk modernisering eller stormaktspolitik? Utrikesmagasinet, Utrikespolitiska Institutet. Hämtad 11. december 2019 från https:/www.ui.se/utrikesmagasinet/analyser/2015/ februari/ekonomisk-modernisering-eller-stormaktspolitik

Lithuanian Delegation of the EPP Group in the European Parliament. (2019). Non-Paper: Our strategy on the future of the Eastern Partnership. Hämtad 19. januari 2020 från https://tsajunga.lt/wp-content/ uploads/2019/10/LT-EPP-Trio-Strategy-2030.pdf

Magen, A. \& Morlino, L. (Red.) (2009). International actors, democratization and the rule of law: Anchoring democracy? New York: Routledge.

Makszimov, V. (2019, 19. november). Large scale corruption undermines EU's Eastern Partnership, official says. EURACTIV. Hämtad 19. januari 2020 från https://www.euractiv.com/section/europe-s-east/news/ large-scale-corruption-undermines-eus-eastern-partnership-official-says

Makszimov, V. (2019b, 21. november). Future of Eastern Partnership: EPP backs trio plan, Commission cautious. EURACTIV, Hämtad 19. januari 2020 från https:/www.euractiv.com/section/europe-s-east/ news/future-of-eastern-partnership-epp-backs-trio-plan-commission-cautious/

Mayer, S. (2014). Common foreign and security policy alignment in the Southern Caucasus: Convergence, "pick and choose» or indifference? Europe-Asia Studies, 66(10), 1679-1702.

Niemann, A. \& Bretherton, C. (2013). EU external policy at the crossroads: The challenge of actorness and effectiveness. International Relations, 27(3), 261-275.

Nilsson, N. (2018, 6. februari). Så här bedriver Ryssland hybridkrigföring mot Georgien. Svenska Dagbladet. Hämtad 8. januari 2020 från https://www.svd.se/niklas-nilsson-sa-har-bedriver-ryssland-hybridkrigforingmot-georgien

Nilsson, N. (2018b). Russian hybrid tactics in Georgia. Silk Road Paper, Central Asia-Caucasus Institute, Silk Road Studies Program. Hämtad 8. januari 2020 från https://silkroadstudies.org/resources/pdf/ SilkRoadPapers/2018_01_Nilsson_Hybrid.pdf

Nitoiu, C. \& Sus, M. (2019). Introduction: The rise of geopolitics in the EU's approach in its Eastern Neighbourhood. Geopolitics, 24(1), 1-19.

Noutcheva, G. (2012). European foreign policy and the challenges of Balkan accession: Conditionality, legitimacy and compliance. London: Routledge.

OSSE:s särskilde representant för mediefrihet. (2019, 21. juni). OSCE Media Freedom Representative deplores violence against media workers during demonstration in Tbilisi. Hämtad 14. januari 2020 från https://www.osce.org/representative-on-freedom-of-media/423824

Palme, S. (2019, 18. oktober). Nordmakedonien och Albanien får vänta. Sveriges Radio. Hämtad 19. januari 2020 från https://sverigesradio.se/sida/artikel.aspx?programid=83\&artikel $=7324787$

Papadimitriou, D., Baltag, D. \& Surubar, N. C. (2017). Assessing the performance of the European Union in Central and Eastern Europe and in its Neighbourhood. East European Politics, 33(1), 1-16.

Papadimitriou. D. \& Petrov, P. (2012). Whole rule, whose law? Contested statehood, external leverage and the European Union's Rule of Law Mission in Kosovo. Fournal of Common Market Studies, 50(5), 746-763.

Radaelli, C. (2003). The Europeanisation of public policy. I K. Featherstone \& C. Radaelli (Red.), The Politics of Europeanisation (s. 27-56). Oxford: Oxford University Press.

RadioFreeEurope/RadioLiberty. (2013, 14. oktober). Russian imports of Georgian fruit resume after seven years. Hämtad 7. januari 2020 från https:/www.rferl.org/a/russia-georgia-fruit-imports/25136096.html

Reportrar utan gränser. (2019). A revolution live-streamed. Hämtad 14. januari 2020 från https://rsf.org/en/ armenia

Reportrar utan gränser. (2019b). Unrelenting war against the last critical voices. Hämtad 14. januari 2020 från https://rsf.org/en/azerbaijan

Rhinard, M. \& Sjöstedt, G. (2019). The EU as a global actor: A new conceptualization four decades after 'actorness'. UI Paper, Utrikespolitiska Institutet. Hämtad 3. december 2019 från https://www.ui.se/ globalassets/ui.se-eng/publications/ui-publications/2019/ui-paper-no.-6-2019.pdf

Richard, Y. \& Van Hamme, G. (2013). The European Union as an actor in international relations: A geographical assessment of European actorness. Cairn. Hämtad 25. januari 2020 från https://www.cairnint.info/article_p.php?ID_ARTICLE=E_EG_421_0015 
Rieker, P. (2016). Introduction. The European Neighbourhood Policy: An instrument for security communitybuilding. I P. Rieker (Red.), External governance as security community building: The limits and potential of the European Neighbourhood Policy (s. 1-17). London: Palgrave Macmillan.

Riksdagen. (2015). Översyn av den europeiska grannskapspolitiken. Utrikesutskottets betänkande, 2015/16:UU5. Hämtad 7. november 2019 från https://www.riksdagen.se/sv/dokument-lagar/arende/ utlatande/oversyn-av-den-europeiska-grannskapspolitiken_H301UU5

Sarkisyan, D. (2017). Tracking and countering anti-European and anti-democratic propaganda in Armenia. Open Society Foundations - Armenia. Hämtad 8. januari 2020 från http://www.osf.am/wp-content/ uploads/2017/11/Tracking-and-Countering-Anti-European-and-Anti-Democratic-Propaganda-inArmenia-policy-brief.pdf

Schimmelfennig, F. (2012). Europeanization beyond Europe. Living Reviews in European Governance, 7(1), 1-24.

Schimmelfennig, F. (2018). Beyond enlargement: Conceptualizing the study of the European Neighbourhood Policy. IT. Schumacher, A. Marchetti \& T. Demmelhuber (Red.), The Routledge handbook on the European Neighbourhood Policy (s. 17-27). Milton Park, Abingdon, Oxon: Routledge.

Schimmelfennig, F. \& Scholtz, H. (2008). EU democracy promotion in the European Neighborhood. European Union Politics, 9(2), 187-215.

Schedler, A. (2002). Elections without democracy: The menu of manipulation. fournal of Democracy, 13(2), 36-50.

Schumacher, T. (2018). The European Neighbourhood Policy: The challenge of demarcating a complex and contested field of study. I T. Schumacher, A. Marchetti \& T. Demmelhuber (Red.), The Routledge handbook on the European Neighbourhood Policy (s. 3-14). Milton Park, Abingdon, Oxon: Routledge.

Sedelmeier, U. (2011). Europeanisation in new member and candidate states. Living Reviews in European Governance, 6(1). Hämtad 21. januari 2020 från http://www.europeangovernance-livingreviews.org/ Articles/lreg-2011-1/

Sjöstedt, G. (1977). The external role of the European community. Farnborough: Saxon House.

Syssoyeva, R. (2019). Understanding the enlargement of the Eurasian Economic Union: The case of Armenia and Kyrgyzstan. Politikon: The IAPSS fournal of Political Science, 40, 48-60.

Söderbaum, F., Stålgren, P. \& Van Langenhove, L. (2005). The EU as a global actor and the dynamics of interregionalism: A comparative analysis. European Integration, 27(3), 365-380.

Tartes, A. (2015). The limited influence of the European Union in Armenia and Azerbaijan: A domestic explanation. EU Diplomacy Paper, 9/2015, College of Europe. Hämtad 3. december 2019 från http://aei. pitt.edu/70371/1/edp\%2D9\%2D2015_tartes_0.pdf

Toje, A. (2008). The consensus-expectations gap: Explaining Europe's ineffective foreign policy. Security Dialogue, 39(1), 121-141.

Vachudova, M. A. (2005). Europe undivided: Democracy, leverage and integration after Communism. Oxford: Oxford University Press.

Vink, M. (2003). What is Europeanisation? And other questions on a new research agenda. European Political Science, 3(1), 63-74.

Vogler, J. \& Bretherton, C. (2006). The European Union as a protagonist to the United States on climate change. International Studies Perspective, 7(1), 1-22.

Whitman, R. G. \& Wolff, S. (2010). Much ado about nothing? The European Neighbourhood Policy in context. I R. G. Whitman \& S. Wolff (Red.), The European Neighbourhood Policy in perspective: context, implementation and impact (s. 3-26). Basingstoke: Palgrave Macmillan.

Wolczuk, K (2009). Implementation without coordination: The impact of EU conditionality on Ukraine under the European Neighbourhood Policy. Europe-Asia Studies, 61(2), 187-211.

Wolczuk, K., Delcour, L., Dragneva, R., Maniokas, K. \& Žeruolis, D. (2017). The Association Agreements as a dynamic framework: Between modernization and integration. EU-Strat Working Paper Series, No. 6. Hämtad 3. december 2019 från http://eu-strat.eu/wp-content/uploads/2017/09/EU-STRAT-WorkingPaper-No.-6.pdf

Wolfschwenger, J. (2019). 10 years Eastern Partnership - the EU and its strategic dilemma. Österreichische Gesellschaft für Europapolitik, ÖGfE Policy Brief 14. Hämtad 18. januari 2020 från https://oegfe.at/ wordpress/wp-content/uploads/2019/06/OEGfE_Policy_Brief-2019.14.pdf

Wrobel, A. (2019, 20. december). It's time for the EU to show Georgia that a clear path towards membership exists. Emerging Europe. Hämtad 19. januari 2020 från https:/emerging-europe.com/news/its-time-forthe-eu-to-show-georgia-that-a-clear-path-towards-membership-exists/

Youngs, R. (2017). Europe's eastern crisis: The geopolitics of asymmetry. Cambridge, United Kingdom: Cambridge University Press. 